principal y ático, elemento éste que, sin embargo, ya en Leganés desaparecerá en detrimento del desarrollo vertical del tema pictórico para potenciar la libertad compositiva del cascarón.

Y por lo que a los retablos laterales se refiere, existe una gran similitud con los también colaterales de Leganés, algo posteriores. Un tipo de dos cuerpos, el inferior con caja de medio punto para la imagen y articulado por cuatro columnas salomónicas; arriba, un ático con medallón circular que alberga el tema pictórico. Pero resultando éstos de Yunclillos, debido quizás a su ubicación, un modelo muy simplificado sin excesivo juego constructivo pero de gran derroche plástico en su coronamiento, pese a la desaparición de elementos de remate que aminoran el efecto de conjunto.

Antonio José DíAZ FernáNDEZ

\title{
EL BOCETO DE FRANCISCO GUTIÉRREZ PARA SU «GLORIA DE SAN PEDRO DE ALCÁNTARA»
}

$\mathrm{Al}$ realizar un estudio en la madrileña iglesia de la Enfermería de la V.O.T., nos encaminamos a la búsqueda del relieve de la «Apoteosis de San Pedro de Alcántara (boceto de obra de empeño) en el lavabo de la Sacristía» de que habla Don Elías Tormo en sus Iglesias del Antiguo Madrid ${ }^{1}$. A primera vista comprobamos que la obra resultaba facilmente identificable como el boceto del gran relieve que preside la capilla, que guarda los restos del Santo, en el monasterio franciscano de San Pedro de Alcántara en la localidad abulense de Arenas de San Pedro donde el santo muere en 1562 (Fig. 4). La obra parece se comienza en 1771 y fue terminada por Francisco Gutiérrez en 1773 estando firmada en su base en una placa de bronce en la que también consta el nombre del donante, D. Pedro de Alcántara de Toledo y Silva, Duque del Infantado. El relieve mide 6,5 ms. de alto por $3 \mathrm{~ms}$. de ancho y está tallado en mármol de Carrara con algunas partes en estuco, resaltando su blancura sobre los mármoles oscuros del marco y los que adornan el presbiterio. El propio escultor acudió al monasterio a la colocación del relieve en el mes de junio de ese año de $1773^{2}$. Sobre el altar se alza el sarcófago de mármoles y bronces que guarda los restos del Santo, para él hizo un modelo Ventura Rodríguez y el hermoso grupo del Ave Fénix que resurge del fuego sigue, al parecer, un modelo de Francisco Gutiérrez ${ }^{3}$. La urna fue donación de los Duques de Medinaceli. Relieve y sarcófago forman una obra bellísima que resalta espléndida en el marco rico y colorista de mármoles y bronces de la capilla del más selecto barroco «romano», realizado según proyecto de Ventura Rodríguez y de la que se coloca la primera piedra el 10 de julio de 1757 según reza el acta conmemorativa del acto conservada en el archivo del monasterio. El 18 de abril de 1771 por Real Cédula fechada en Aranjuez, el rey Carlos III declaraba a la capilla

1 Elías Tormo: Las Iglesias del Antiguo Madrid, Madrid, Instituto de España, 1972, p. 63.

2 Fr. José Trinidad: Guía ilustrada del Santuario de San Pedro de Alcántara, Segovia, 1958, p. 85. Ver también Fr. Anastasio Navarro y Fr. Antonio Muñoz: San Pedro de Alcántara. Gloria de su Sepulcro en su Santuario de Arenas de San Pedro, Ávila, 1968, pp. 27 y 28 y de modo especial Fr. Vicente de Estremera: Sucesos ocurridos durante la obra de la Capilla de San Pedro de Alcántara, Caja de Ahorros de Ávila, 1977, p. 346.

Es frecuente entre quienes se refieren al relieve de San Pedro el comentario de estar realizado en estuco. En realidad está trabajado en mármol las partes principales y estuco el conjunto de nubes. La confusión se debe en parte al hecho de haber sido todo él bañado con una capa de albayalde buscando una mayor blancura del conjunto.

3 Fr. Vicente de Estremera, o.c., pp. 219 y 222. 


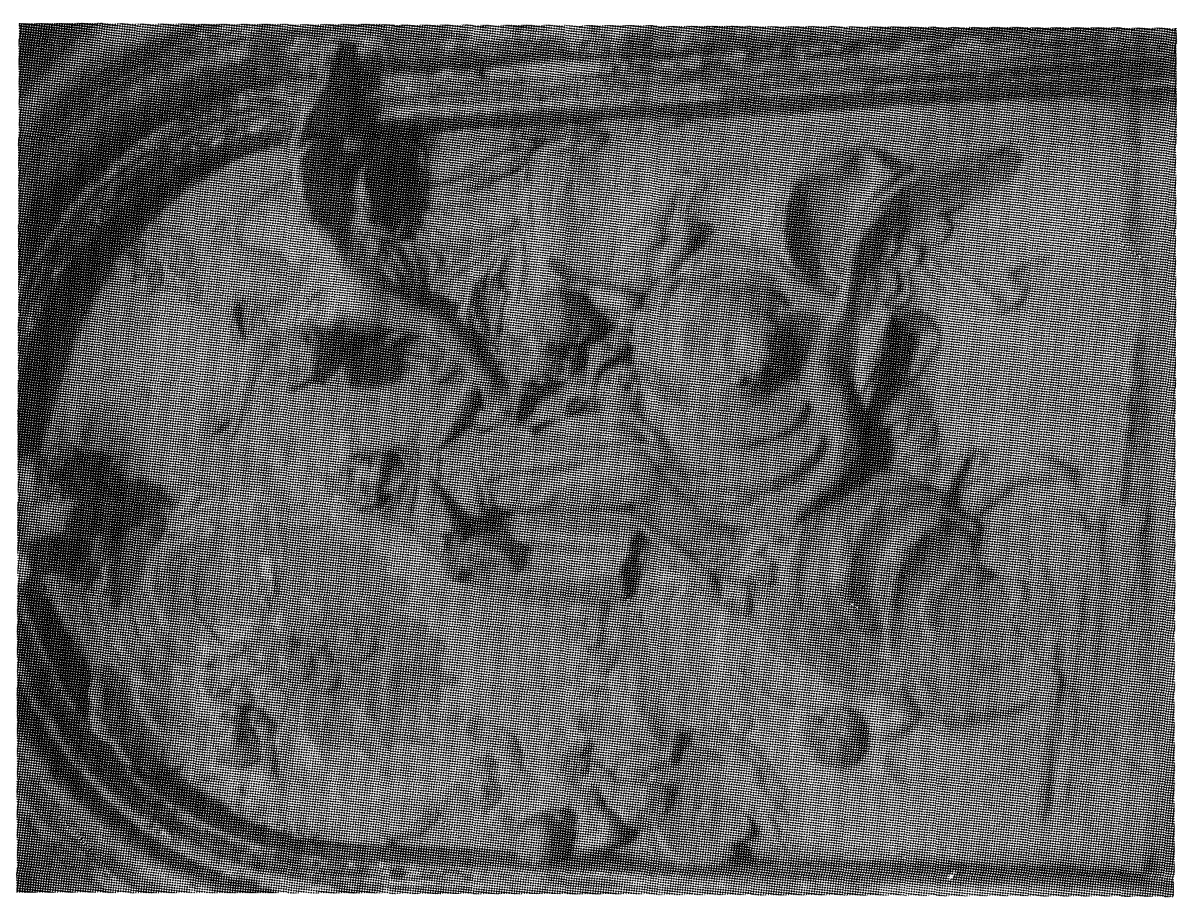

n

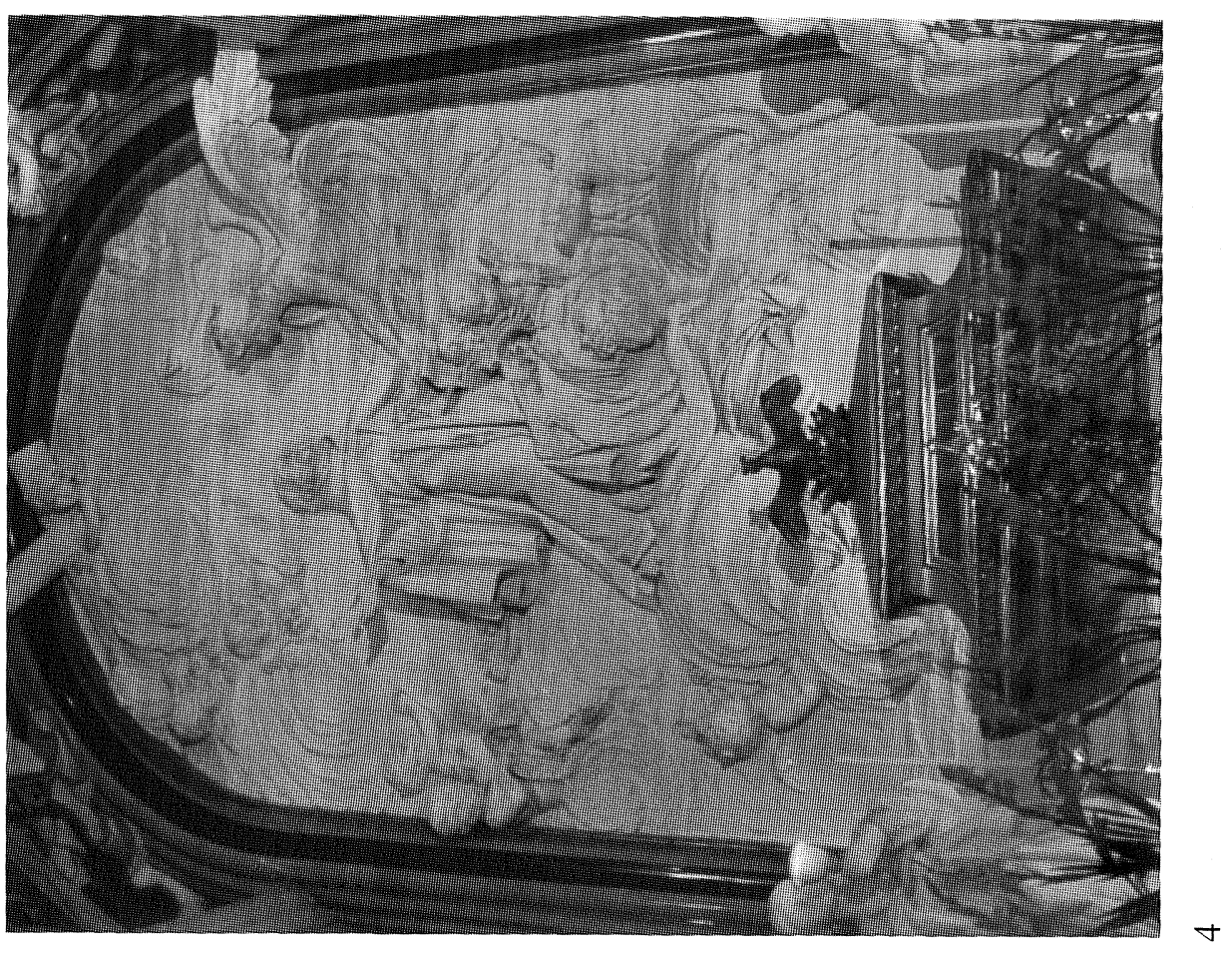

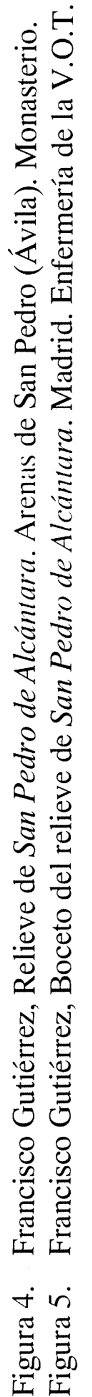


de Real Patronato ${ }^{4}$. Para su construcción intervinieron con sus limosnas Carlos III, incluso siendo aun rey de Nápoles, los miembros más influyentes de la nobleza de entonces como ya hemos visto, el pueblo llano e incluso llegaron limosnas de América, pero el verdadero alma e impulsor de toda la empresa fue el fraile Fray Vicente de Estremera quien felizmente dejó un libro manuscrito testimonio de sus infinitos afanes de imprescindible consulta.

El boceto de la Enfermería de la V.O.T., del que ningún documento concreto hemos localizado, reproduce el relieve definitivo con absoluta fidelidad, mide aproximadamente 0,72 x 0,43 ms., y en él aparecen el Santo sobre un trono de nubes que eleva un bello ángel mancebo (Fig. 5). San Pedro, arrodillado y en éxtasis, mira a otro ángel que le señala una cruz que en el extremo superior porta uri angelillo ${ }^{5}$. Por todo el conjunto se mueven ángeles niños, portando algunos de ellos símbolos de penitencia, y cabezas de serafines. La única diferencia digna de mención con la obra definitiva nos parece localizarla en el rostro del Santo, que se nos muestra más natural y menos arrobado en el boceto que en la obra definitiva. El estado de conservación de la pieza, realizado en escayola o estuco sobre una fina lámina de madera, no es malo pero hay señales de alarma que aconsejan una pronta intervención, algunas partes se van desprendiendo, el Santo ha perdido la mano derecha y todo el conjunto del marco se ve seriamente amenazado por la misma fragilidad del material.

Muy posiblemente este boceto fue presentado al Duque del Infantado por el propio Francisco Gutiérrez el día 4 de febrero de 1772, aunque ya conocía otro menor, su aprobación fue total y ello influyó poderosamente en su ánimo para hacerse cargo del costo ${ }^{6}$. En el retablo definitivo de la capilla, sobre el gigantesco relieve, tres angelillos portan una aborrocada cartela en la que se lee «ET ERIT SEPULCHUM EIUS GLORIOSUM», que no aparecen en el boceto y que Gutiérrez colocó cuando estuvo en Arenas para llevar y colocar la medalla.

El conjunto del retablo fue magistralmente grabado por Manuel Salvador Carmona según decisión personal del infatigable fray Vicente de Estremera. Para ello mandó hacer dos dibujos del conjunto uno de los cuales, al menos, fue mostrado al Rey y, aunque los datos documentales manejados no son lo preciso que hubiesemos deseado, es posible que en ellos interviniesen Fernando Selmas. El grabado fue costeado también por el Duque de Medinaceli quien quiso que se dedicase al Rey. Carmona, que lo firma en 1775, cobró por su trabajo 16 ducados reales y Fray Vicente a quien todo este asunto costó muchos sinsabores entusiasmado con la lámina escribe, «no dudo que sea una de las piezas de las mejores que se hayan abierto en Europa» ${ }^{7}$ (Fig. 6).

En el grabado aparecen, a uno y otro lado del sepulcro, las efigies de la Fe y la Humildad que siguen la iconografía de Cesare Ripa ${ }^{8}$. Según los documentos del monasterio la historia de su talla aparece confusa pero Cean ya las da por realizadas en su Diccionario ${ }^{9}$. Desapare-

${ }^{4}$ Fr. José Trinidad: o.c., Fr. Anastasio Navarro y Fr. Antonio Muñoz: o.c., Fr. Vicente de Estremera: o.c. Ver también Fr. Julio Herranz Migueláñez: Catálogo del archivo del Convento Franciscano de San Pedro de Alcántara en Arenas de San Pedro, 1493-1900, Diputación Provincial de Ávila y Caja de Ahorros de Ávila, 1996, p. 196. Fernando Chueca Goitia: «Ventura Rodríguez y la Escuela Barroca Romana» y Pedro Navascués Palacio: «Ventura Rodríguez entre el Barroco y el Neoclasicismo» en el catálogo de la exposición sobre El Arquitecto D. Ventura Rodríguez (1717-1785), Museo Municipal de Madrid, 1983, pp. 11-33 y 111-130.

5 Los ángeles de esta composición, particularmente los dos ángeles mancebos, responden al mismo esquema y espíritu que el ángel que sostiene la casulla de San Ildefonso en el relieve de Manuel Álvarez en la Catedral de Toledo, composición de la que casualmente también nos ha llegado el boceto (Fig. 7). Ver F. de Borja San Román: «Museo Arqueológico Provincial» en Toledo. Guía Oficial, Gómez Menor, 1928, p. 7 y Juan Nicolau Castro: Escultura Toledana del siglo XVIII, Toledo, IPIET, 1991, pp. 213-215.

6 Fr. Vicente de Estremera: o.c., pp. 227-28.

Idem, pp. 352-53.

8 Cesare Ripa: Iconologia, E. Akal, Madrid, 1987, T. I, pp. 401 y 499.

J. A. Cean Bermúdez: Diccionario Histórico..., Madrid, 1800, T. II, p. 250. 


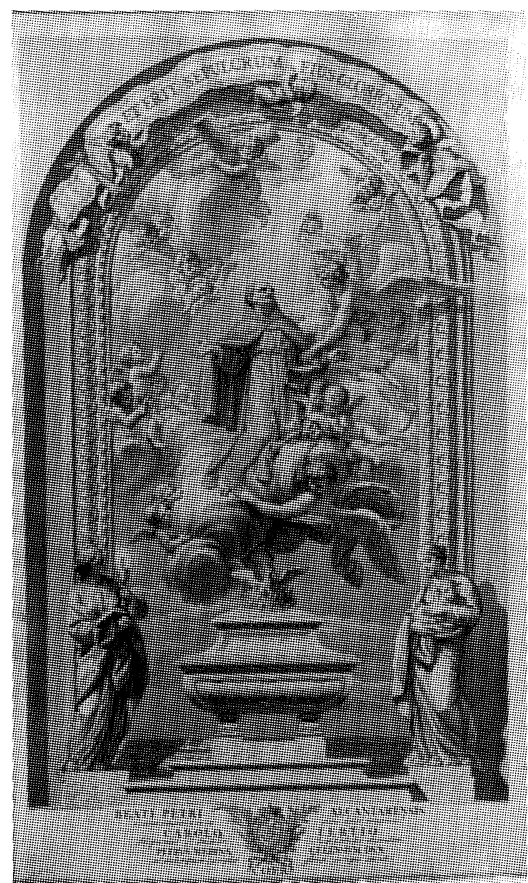

6
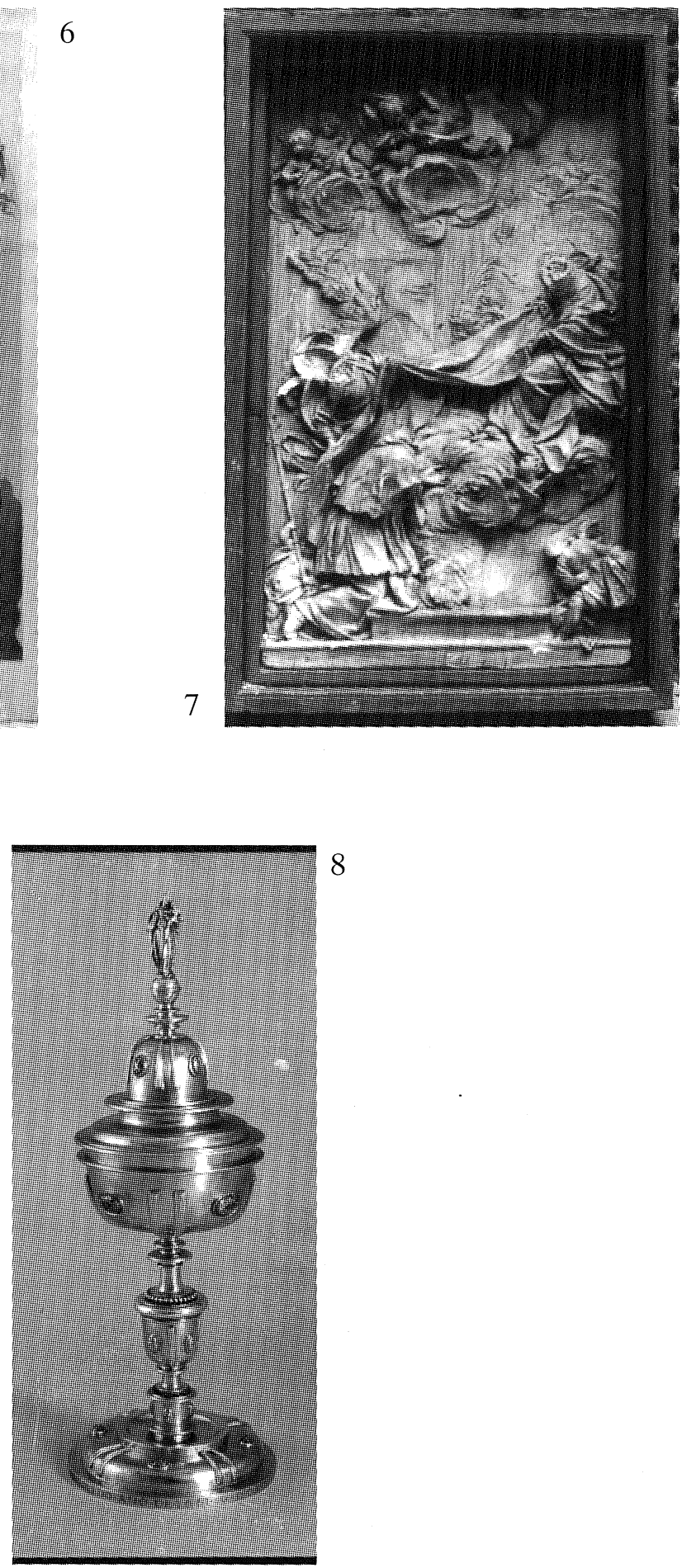

Figura 6. Manuel Salvador Carmona. Grabado del Altar de San Pedro de Alcántara. Arenas de San Pedro. (Ávila). Monasterio.

Figura 7. Manuel Álvarez. Boceto del relieve de la Descensión de la Virgen. Toledo. Museo de Santa Cruz. Figura 8. Francisco de Salinas. Copón. Mercado de arte. 
cidas, tal vez durante la Francesada, las actuales son obra del escultor Ricardo Font y fueron colocadas en $1948^{10}$.

El gran relieve de San Pedro es obra absolutamente barroca, inspirada en las apoteosis de santos que se multiplican en las iglesias de la ciudad de Roma y nos apuntan a la larga estancia de Francisco Gutiérrez en la Ciudad Eterna y a su aprendizaje con Giovanni Battista Maini de tradición aun berninesca ${ }^{11}$. El escultor pese a sus ideales académicos no pudo sustraerse al efectismo teatral de las grandes composiciones del barroco tan acordes con una manera muy popular de entender y explicar el hecho religioso.

Nada seguro podemos apuntar a cómo llegó esta pieza a la sacristía de la Enfermería de la V.O.T., pero es lógico pensar en una donación muy posiblemente del propio escultor a quien sabemos relacionado en algún momento con la V.O.T. y sobre todo con el desaparecido convento franciscano de San Gil de los barrios madrileños de Afligidos y Leganitos.

Juan Nicolau Castro

Academia de Bellas Artes de Toledo

\section{UNA OBRA INÉDITA DE 1661 DEL PLATERO FRANCISCO DE SALINAS}

El estudio de la Platería suscita cada día mayor interés entre los especialistas y los interesados por la Historia del Arte tanto fuera como dentro de nuestras fronteras. Testimonio de ello son tanto las publicaciones referentes como las continuas apariciones de piezas de plata en el comercio internacional de arte.

$\mathrm{Si}$ bien es cierto que son muchas las obras de arte que no habitan hoy en el escenario para el que fueron concebidas, en el caso de las obras de plata los gustos de la época, las modas, el deseo del coleccionista han propiciado el traslado o la fundición haciéndolas en muchos casos susceptibles de pérdida o difícil localización, por lo que la tarea del investigador se hace más ardua. Es por todo ello por lo que en este trabajo queremos dar a conocer una obra que ha llegado a traspasar el umbral de nuestro país pero afortunadamente no de nuestra investigación.

Tras esta pretensión late el deseo de no dejar escapar al conocimiento científico una pieza de carácter inédito, obra de especial interés no solamente por sus características peculiares que la afilian sin duda a la platería de Toledo, sino también por su calidad (Fig. 8).

La pieza es un copón de plata sobredorada con esmaltes opacos de color azul y detalles ambarinos. Mide 46,3 cms. de altura y presenta buen estado de conservación. En el borde vertical del pie puede leerse la inscripción: «DIO ESTE COPON DE LIMOSNA EL LLDO ROQVE DE HRRERA RAC ${ }^{o}$ DE LA SANTA YGLESIA DE TOLEDO ANO DE 1661». En el interior del pie marca: SA/LINS.

La obra ha aparecido en el comercio londinense y en su catalogación se habla de una obra estilo Herrera datable cerca de 1620. Las afirmaciones relativas a material, estado de conservación, medidas, parece que responden a la realidad, pero sin duda, la fecha ofrecida no resulta convincente.

Tampoco la interpretación tanto de la marca como de la inscripción que ostenta la pieza parece la más acertada tal como a continuación expondremos. El copón se clasifica como

${ }^{10}$ Fr. A. Navarro y Fr. A. Muñoz: o.c., p. 34.

11 Francisco Portela: «Francisco Gutiérrez y el sepulcro del Rey Fernando VI», en El Arte en las Cortes Europeas del siglo XVIII, Comunidad de Madrid, 1987, pp. 599-607. 